\title{
Leptomeningeal Relapse of Acute Promyelocytic Leukemia
}

\author{
Tarik Hadid ${ }^{\mathrm{a}, \mathrm{c}}$, Salman Fazal ${ }^{\mathrm{b}}$, John Lister ${ }^{\mathrm{b}}$
}

\begin{abstract}
Extramedullary relapse (EMR) of acute promyelocytic leukemia (APL) is a rare entity, with predilection to involve the central nervous system (CNS). Risk factors include leukocytosis of $>10 \times$ $10^{9} / \mathrm{L}$, bcr3 isoform, microgranular variant, age $>45$ years and development of subarachnoid hemorrhage (SAH) during induction therapy. We report a case of APL who completed induction and consolidation therapy but subsequently relapsed with leptomeningeal involvement. Retrospectively, we identified several risk factors for EMR in our patient. Interestingly, the use of all-trans retinoic acid has recently been associated with higher risk of EMR possibly due to up-regulation of adhesion molecules on the surface of the leukemic cell, resulting in their passage through the endothelium to extramedullary tissues. However, data remain conflicting in that regard. Although universal CNS prophylaxis has been suggested, the low incidence of EMR among APL patients renders this strategy less attractive. Nonetheless, active surveillance and CNS prophylaxis may be considered in patients at high risk for EMR, particularly in those of SAH during induction therapy. Further research is needed to evaluate the effectiveness and safety of this strategy.
\end{abstract}

Keywords: Acute promyelocytic leukemia; Extramedullary relapse; Leptomeningeal relapse

\section{Introduction}

Acute promyelocytic leukemia (APL) is a highly curable myeloid neoplasm with the majority of failures attributed to

\footnotetext{
Manuscript accepted for publication March 17, 2013

${ }^{\mathrm{a}}$ Van Elslander Cancer Center, St. John Providence Health System, Grosse Pointe Woods, Michigan, USA

${ }^{\mathrm{b}}$ Division of Hematology and Cellular Therapy, Western Pennsylvania Cancer Institute, West Penn Allegheny Health System, Pittsburgh, Pennsylvania, USA

${ }^{\mathrm{c} C}$ Corresponding author: Tarik Hadid, Van Elslander Cancer Center, 19229 Mack Avenue, Suite 23, Grosse Pointe Woods, MI 48236, USA. Email: tarik.hadid@stjohn.org
}

doi: http://dx.doi.org/10.14740/wjon761w early hemorrhagic complications [1,2]. Extramedullary relapse (EMR) with or without concomitant medullary relapse has rarely been described in the medical literature. In this report, we discuss a case of APL with central nervous system (CNS) relapse that occurred 2 months after completion of consolidation therapy. We also review various risk factors for EMR and propose a surveillance strategy to be considered in patients at high risk for EMR.

\section{Case Report}

A 66-year-old woman presented with a 2 weeks history of fever, exertional dyspnea and generalized weakness. Physical examination was unremarkable except for temperature of $38.7^{\circ} \mathrm{C}$ and scattered ecchymoses. Complete blood count revealed WBC of $26.5 \times 10^{9} / \mathrm{L}$ with $75 \%$ blasts, hemoglobin of $9.1 \mathrm{~g} / \mathrm{dL}$, platelet of $15 \times 10^{9} / \mathrm{L}$ and lactate dehydrogenase (LDH) of 2,039 IU/L. Peripheral smear revealed immature cells with irregular, lobulated nuclear contour, scant cytoplasm, fine granules and occasional Auer rods. Bone marrow aspiration and biopsy confirmed the diagnosis of microgranular variant of APL. Cytogenetic and molecular testing detected the presence of bcr3 of PML-RAR $\alpha$ consistent with $\mathrm{t}(15 ; 17)(\mathrm{q} 22 ; \mathrm{q} 21)$. She was initiated on induction therapy with all-trans retinoic acid (ATRA) $45 \mathrm{mg} / \mathrm{m}^{2}$ twice daily until complete remission (CR) and idarubicin $12 \mathrm{mg} /$ $\mathrm{m}^{2}$ daily on day 2, 4, 6 and 8 [3]. Unfortunately, treatment course was complicated by subarachnoid hemorrhage (SAH) and severe differentiation syndrome requiring mechanical ventilation and interruption of therapy on day 5 . She subsequently recovered and resumed induction therapy with single agent ATRA and achieved complete cytogenetic and hematological remission but molecular remission was not confirmed. Due to a poor performance status, she was not a candidate for consolidation chemotherapy and therefore, received consolidation therapy with ATRA for 8 cycles and arsenic trioxide (ATO) for 4 cycles [4]. Two months after completion of therapy, she developed progressive headaches and severe photophobia. At that time, WBC was $6.6 \times 10^{9} / \mathrm{L}$ with no abnormal cells, hemoglobin of $12.3 \mathrm{~g} / \mathrm{dL}$, platelet of $227 \times 10^{9} / \mathrm{L}$ and $\mathrm{LDH}$ of $146 \mathrm{IU} / \mathrm{L}$. Magnetic resonance im- 


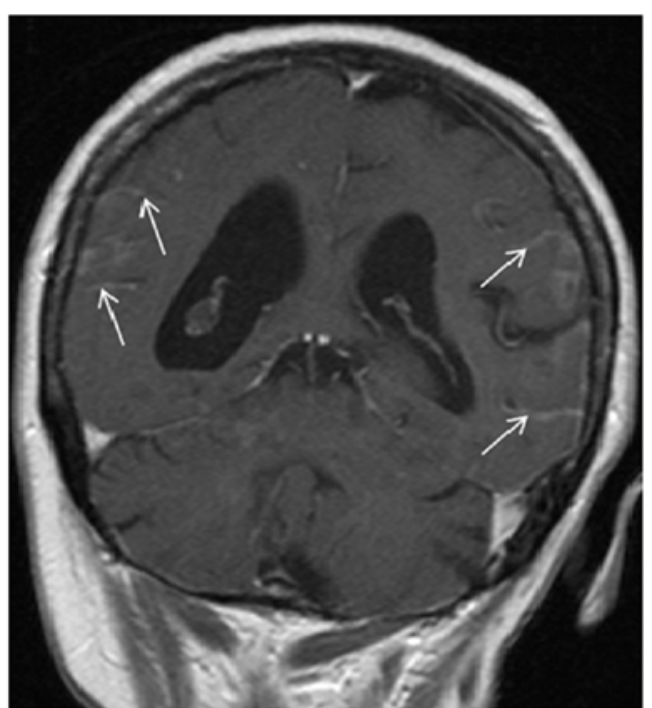

Figure 1. T1-weighted MRI image showing leptomeningeal enhancement (arrows).

aging (MRI) of the brain showed extensive leptomeningeal enhancement (Fig. 1). Cerebrospinal fluid (CSF) was very cellular with many immature cells with morphology similar to that seen in the bone marrow at initial diagnosis (Fig. 2). Additionally, flow cytometry detected a similar immunophenotype to that noted at initial diagnosis. Despite continued hematological and cytogenetic remission, reverse transcription polymerase chain reaction of peripheral blood detected the brc3 isoform of PML-RAR $\alpha$ confirming molecular relapse. She was treated with repeated courses of intrathecal methotrexate and cytarabine. With therapy, she showed clinical improvement and resolution of her symptoms with clearance of her CSF. Systemic therapy was deferred to the outpatient setting given her poor performance status. She was non-compliant and lost to follow-up.

\section{Discussion}

EMR, as in our patient, is rarely reported in patients treated for APL [5, 6]. EMR can occur in the CNS [5-11], skin [5, 6, $9,12]$, middle ear [5, 9, 11, 13], lung [5], pleura [14], sites of vascular access [12] and sites of bone marrow aspiration and biopsy [12]. However, CNS is the predominate site of EMR with an estimated risk of 0.6 to $2 \%[5,6]$. Several risk factors for EMR have been identified. One European study found leukocytosis $\left(>10 \times 10^{9} / \mathrm{L}\right)$, bcr3 isoform of PMLRAR $\alpha$ and younger age ( $<45$ years) to be significantly associated with higher risk for EMR. However, only leukocytosis was found to be significant on multivariate analysis [6]. In addition, SAH during induction therapy and microgranular variant were found to portend higher risk of EMR in other studies [15-17]. In fact, the probability of EMR approaches

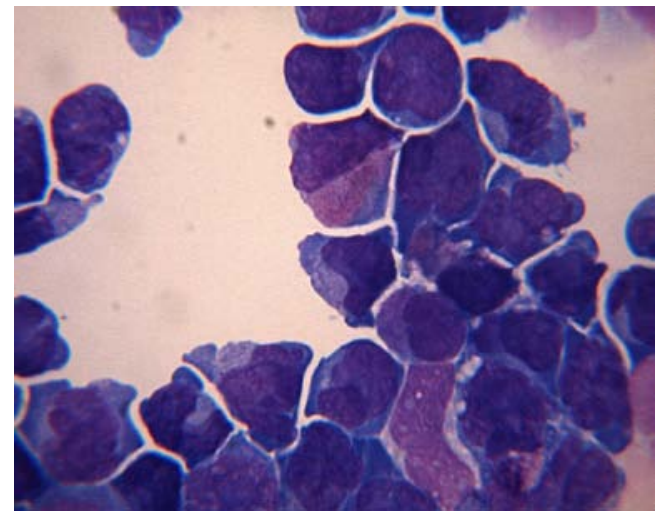

Figure 2. Cerebrospinal fluid is hypercelluar with numerous hypogranular promyelocytes.

$19 \%$ in those with SAH compared to $1 \%$ in those without SAH [17]. This may be due to leukemic cells seeding the leptomeninges when SAH occurs. Notably, our patient has multiple risk factors including leukocytosis, bcr3 isoform, microgranular variant and SAH during induction therapy, which placed her at significant risk for CNS relapse.

Within the last two decades, there has been significant concern regarding the association between the use of ATRA and the emergence of EMR. It has been hypothesized that ATRA may up-regulate cellular adhesion molecules expressed on the surface of leukemic cells such as CD11a, CD11b, CD11c and CD45RO. Binding of these molecules to their ligands expressed on endothelial cells may result in passage of these cells through the endothelium, which results in EMR $[8,15,18,19]$. To test this hypothesis, Specchia et al reviewed the outcome of two consecutive studies of the "Gruppo Italiano Malatie Ematologiche dell'Adulto" and found no significant association between ATRA and EMR. However, there was a worrisome trend toward higher incidence of EMR among the ATRA group (12\% versus $5 \%, \mathrm{P}$ $=0.08)$. Furthermore, the pattern of EMR was different between the two cohorts with those who received ATRA suffering higher CNS relapses compared to the chemotherapyonly cohort ( $8 \%$ versus $1 \%, \mathrm{P}=0.02$ ) [5]. Therefore, CNS relapse remains a concern in patients who receive ATRA, particularly in the presence of other risk factors, as in our patient. Whether these findings represent a true association or merely a consequence of improved survival of APL patients remains to be established.

There is no consensus on the best strategy to treat EMR. The majority of reported cases were treated with intrathecal chemotherapy with or without radiation therapy $[6,8,10]$. ATRA, ATO and/or chemotherapy were also used to treat systemic disease when present simultaneously $[11,13,19-$ 21]. Unfortunately, ATRA has limited penetration to CNS and therefore, is used primarily to treat systemic disease [22]. In addition, no CR was observed with ATRA in relapses occurring within 4 months of discontinuation of ATRA, as 
in our patient [23]. Conversely, ATO efficiently penetrates the CSF and achieves levels that correlate linearly with and approach $30-50 \%$ of the plasma levels [24, 25]. Although these findings suggest that this agent might effectively treat and prevent CNS relapse, its occurrence in our patient after receiving four 8-week cycles of ATO argues otherwise. Systemic ATO might be inadequate for prophylaxis for CNS relapse. Several authors advocate routine intrathecal chemotherapy for CNS prophylaxis in high-risk APL patients [26]. However, the low incidence of CNS relapse argues against this strategy. Nonetheless, selective surveillance and prophylaxis of individuals with high and/or multiple risk factors for CNS relapse after achieving CR may be more appropriate in successfully preventing CNS relapse while avoiding unnecessary risky interventions. Further study of surveillance and prophylaxis strategy to prevent CNS relapse in APL patients is needed to standardize therapy for this increasingly curable disease.

\section{Financial Disclosure Statement}

All authors disclose that they have no financial interests related to this manuscript.

\section{References}

1. Douer D, Zickl LN, Schiffer CA, Appelbaum FR, Feusner JH, Shepherd L, Willman CL, et al. All-trans retinoic acid and late relapses in acute promyelocytic leukemia: very long-term follow-up of the North American Intergroup Study I0129. Leuk Res. 2013;37(7):795-801.

2. Park JH, Qiao B, Panageas KS, Schymura MJ, Jurcic JG, Rosenblat TL, Altman JK, et al. Early death rate in acute promyelocytic leukemia remains high despite alltrans retinoic acid. Blood. 2011;118(5):1248-1254.

3. Mandelli F, Diverio D, Avvisati G, Luciano A, Barbui $\mathrm{T}$, Bernasconi C, Broccia $\mathrm{G}$, et al. Molecular remission in PML/RAR alpha-positive acute promyelocytic leukemia by combined all-trans retinoic acid and idarubicin (AIDA) therapy. Gruppo Italiano-Malattie Ematologiche Maligne dell'Adulto and Associazione Italiana di Ematologia ed Oncologia Pediatrica Cooperative Groups. Blood. 1997;90(3):1014-1021.

4. Estey E, Garcia-Manero G, Ferrajoli A, Faderl S, Verstovsek S, Jones D, Kantarjian H. Use of all-trans retinoic acid plus arsenic trioxide as an alternative to chemotherapy in untreated acute promyelocytic leukemia. Blood. 2006;107(9):3469-3473.

5. Specchia G, Lo Coco F, Vignetti M, Avvisati G, Fazi P, Albano F, Di Raimondo F, et al. Extramedullary involvement at relapse in acute promyelocytic leukemia patients treated or not with all-trans retinoic acid: a report by the
Gruppo Italiano Malattie Ematologiche dell'Adulto. J Clin Oncol. 2001;19(20):4023-4028.

6. de Botton S, Sanz MA, Chevret S, Dombret H, Martin G, Thomas X, Mediavilla JD, et al. Extramedullary relapse in acute promyelocytic leukemia treated with all-trans retinoic acid and chemotherapy. Leukemia. 2006;20(1):35-41.

7. Akoz AG, Dagdas S, Ozet G, Ceran F, Yilmaz M. Isolated central nervous system relapse during cytologic and molecular hematologic remission in two patients with acute promyelocytic leukemia. Hematology. 2007;12(5):419-422.

8. Burry LD, Seki JT. CNS relapses of acute promyelocytic leukemia after all-trans retinoic acid. Ann Pharmacother. 2002;36(12):1900-1906.

9. Evans GD, Grimwade DJ. Extramedullary disease in acute promyelocytic leukemia. Leuk Lymphoma. 1999;33(3-4):219-229.

10. Housman E, Chang P, Lane SW, Blinder R, Galinsky I, Kesari S, Ho VT, et al. CNS relapse in acute promyeloctyic leukemia. J Clin Oncol. 2010;28(24):e409-411.

11. Vega-Ruiz A, Faderl S, Estrov Z, Pierce S, Cortes J, Kantarjian H, Ravandi F. Incidence of extramedullary disease in patients with acute promyelocytic leukemia: a single-institution experience. Int J Hematol. 2009;89(4):489-496.

12. Sanz MA, Larrea L, Sanz G, Martin G, Sempere A, Gomis F, Martinez J, et al. Cutaneous promyelocytic sarcoma at sites of vascular access and marrow aspiration. A characteristic localization of chloromas in acute promyelocytic leukemia? Haematologica. 2000;85(7):758-762.

13. Lafayette TC, Coser VM, Brule AO, Coser PL, Pereira WV. External auditory canal and middle ear relapse of acute promyelocytic leukemia treated with arsenic trioxide: case report and review of the literature. J Pediatr Hematol Oncol. 2010;32(3):229-232.

14. Disel U, Yavuz S, Paydas S, Sahin B, Zeren H. Extramedullary relapse in the pleura in acute promyelocytic leukemia. Leuk Lymphoma. 2003;44(1):189-191.

15. Di Noto R, Lo Pardo C, Schiavone EM, Ferrara F, Manzo C, Vacca C, Del Vecchio L. All-trans retinoic acid (ATRA) and the regulation of adhesion molecules in acute myeloid leukemia. Leuk Lymphoma. 1996;21(34):201-209.

16. Colovic N, Bogdanovic A, Miljic P, Jankovic G, Colovic M. Central nervous system relapse in acute promyelocytic leukemia. Am J Hematol. 2002;71(1):60-61.

17. Montesinos P, Diaz-Mediavilla J, Deben G, Prates V, Tormo M, Rubio V, Perez I, et al. Central nervous system involvement at first relapse in patients with acute promyelocytic leukemia treated with all-trans retinoic acid and anthracycline monochemotherapy without intrathecal prophylaxis. Haematologica. 2009;94(9):12421249 . 
18. Di Noto R, Schiavone EM, Ferrara F, Manzo C, Lo Pardo C, Del Vecchio L. All-trans retinoic acid promotes a differential regulation of adhesion molecules on acute myeloid leukaemia blast cells. Br J Haematol. 1994;88(2):247-255.

19. Avvisati G, Lo Coco F, Diverio D, Falda M, Ferrara F, Lazzarino M, Russo D, et al. AIDA (all-trans retinoic acid + idarubicin) in newly diagnosed acute promyelocytic leukemia: a Gruppo Italiano Malattie Ematologiche Maligne dell'Adulto (GIMEMA) pilot study. Blood. 1996;88(4):1390-1398.

20. Au WY, Ma SK, Ooi C, Liang R, Kwong YL. Unusual manifestations of acute leukemia. Case 1. CNS extramedullary relapse of acute promyelocytic leukemia after arsenic trioxide-induced remission. J Clin Oncol. 2000;18(19):3435-3437.

21. Anguita E, Villegas A, Gonzalez FA, Diaz-Mediavilla J, Lo Coco F. Acute promyelocytic leukemia relapse in the central nervous system during hematologic and molecular remission. Am J Hematol. 1999;60(2):170-171.

22. Muindi JR, Frankel SR, Huselton C, DeGrazia F, Garland WA, Young CW, Warrell RP, Jr. Clinical pharmacol- ogy of oral all-trans retinoic acid in patients with acute promyelocytic leukemia. Cancer Res. 1992;52(8):21382142.

23. Delva L, Cornic M, Balitrand N, Guidez F, Miclea JM, Delmer A, Teillet F, et al. Resistance to all-trans retinoic acid (ATRA) therapy in relapsing acute promyelocytic leukemia: study of in vitro ATRA sensitivity and cellular retinoic acid binding protein levels in leukemic cells. Blood. 1993;82(7):2175-2181.

24. Au WY, Tam S, Fong BM, Kwong YL. Determinants of cerebrospinal fluid arsenic concentration in patients with acute promyelocytic leukemia on oral arsenic trioxide therapy. Blood. 2008;112(9):3587-3590.

25. Au WY, Tam S, Kwong YL. Entry of elemental arsenic into the central nervous system in patients with acute promyelocytic leukemia during arsenic trioxide treatment. Leuk Res. 2008;32(2):357-358.

26. Sanz MA, Grimwade D, Tallman MS, Lowenberg B, Fenaux P, Estey EH, Naoe T, et al. Management of acute promyelocytic leukemia: recommendations from an expert panel on behalf of the European LeukemiaNet. Blood. 2009;113(9):1875-1891. 